\title{
Vacuum ambulance for transporting accessible patient
}

\author{
Marta Blahova \\ Tomas Bata University in Zlín \\ Nad Stráněmi 4511 \\ 76005 Zlín, Czech Republic \\ +420737908114 \\ m6_blahova@utb.cz
}

\author{
Martin Hromada \\ Tomas Bata University in Zlín \\ Nad Stráněmi 4511 \\ 76005 Zlín, Czech Republic \\ +420737908114 \\ hromada@utb.cz
}

\begin{abstract}
The paramedic uses his / her personal potential, ie knowledge, experience, and abilities. They must also be able to handle medical equipment and medical devices, know how to use the forms of control and care. A person infected with a highly dangerous disease. A situation that can really happen. Even in Europe. How to solve patient transport, how to protect his health and how to protect others from infection - all this is dealt with by a special ambulance car, which was developed in Zlín, where the University of Zlín also cooperated. The ambulance is an integral part of the Integrated Rescue System in the event of an emergency with a highrisk infection. For example, it may be MERS, SARS or Ebola. Performance of activities in relation to maintenance, care and, in particular, control of medical devices, the priority of the medical rescue service is the actual performance of the activity of the emergency medical service. Every paramedic should have an accurate idea of how to treat, care and care for a particular medical device and take care of him.
\end{abstract}

Keywords EMS, Vehicle, Equipment, Diseases.

\section{INTRODUCTION}

A highly feared threat is the highly contagious diseases that cause and serious health, social and economic problems today. Throughout its development, the human organism is surrounded by microorganisms whose existence is constantly threatened by the human population. But with rapid advances in infectious medicine, epidemiology, hygiene, preventive medicine, and other medical disciplines, some past epidemics have been wiped out. Preventive vaccination, as well as hygiene measures, account for a large proportion. Nowadays, exotic areas are increasingly visited, and migration of people from all over the world to our country is increasing, which may pose a significant risk of infectious diseases being introduced from other countries, so it is important to know about imported infectious diseases such as hemorrhagic fever, malaria. , SARS and others. In addition to the theoretical knowledge of highly contagious diseases, patients with a confirmed diagnosis or only suspected of having a highly contagious disease need to be able to take care of them. It is not only about the care and treatment of the patient, but also about preventing the spread of infectious disease, ensuring safe work with the patient and ensuring safe transport of the patient to a dedicated workplace for that purpose. Therefore, the so-called Biohazard team was established

SAMPLE: Permission to make digital or hard copies of all or part of this work for personal or classroom use is granted without fee provided that copies are not made or distributed for profit or commercial advantage and that copies bear this notice and the full citation on the first page. To copy otherwise, or republish, to post on servers or to redistribute to lists, requires prior specific permission and/or a fee.

Conference'10, Month 1-2, 2010, City, State, Country.

Copyright 2010 ACM 1-58113-000-0/00/0010 ...\$15.00.

DOI: http://dx.doi.org/10.1145/12345.67890 in the Czech Republic, whose function is provided by the members of the Integrated Rescue System in cooperation with the body for the protection of public health. [1]

\section{HIGLY CREATIVE DISEASES}

According to the South Moravian Region Emergency Response Directive: "Highly infectious disease (VNN) is a locally unusual (exotic), infectiously spreading infectious disease, especially with severe clinical course in the acute phase, potentially high mortality, or often passing into chronicity, or leaving serious permanent clinical consequences. "[1]

\section{IMPORTED DISEASES}

Imported infections are diseases that arose after staying abroad, manifested by clinical signs only after returning to their homeland. Increased tourism has the largest share in the frequency of imported diseases and migration. Importing animals, contaminated food, feed, and articles is another possible risk of importation of imported disease. Generally, imported infections can be caused by bacteria, viruses, protozoa, worms, and microscopic fungi. Early diagnosis and early initiation of treatment are required for imported diseases to prevent lethal endings in some diseases and to prevent further spread of infection. Early diagnosis in some infectious diseases is difficult for long incubation times and atypical clinical signs. For example, in three-day malaria, amebiasis, or leishmaniasis, clinical symptoms may occur after a few months to years from the end of the endemic area. Several imported diseases are reported and some have to be isolated from the infectious department. [2]

Primarily, the introduction of an imported infection threatens primarily foreign travelers, a laboratory worker and persons working with imported animals. Another possible threat with the imported disease is in the case of persons in the secondary contact and it is mainly the employees of quick medical assistance, doctors and nurses of practical outpatient departments, employees in laboratories, inpatient departments, pathology and funeral services.and ambulance workers. [3]

\section{PROTECTIVE EQUIPMENT AND SAFETY IN THE PERFORMANCE OF HEAL RESCUE}

Great emphasis is placed on personal health protection against infection as well as on compliance with hygiene principles. Therefore, personal protection rules must be maintained when contacting an infected person. Every employer of the Emergency Medical Service (hereinafter referred to as the Emergency Medical Service) is obliged to provide protective equipment at the workplace and the employee is obliged to use this personal protective equipment (hereinafter referred to as PPE). PPE are 
individuals and provide protection only to a specific employee against risk factors. The aids are subject to certification and must meet the requirements of applicable legislation - Government Order No. 21/2003 Coll., Which lays down technical requirements for personal protective equipment. In addition to the use of PPE, it is a very important part of performing your profession to observe personal hygiene, consisting of cleaning hands with subsequent disinfection according to the Methodological Manual for Hand Washing of the Ministry of Health. [3]

\section{SPECIAL PROTECTIVE CLOTHING WHEN HANDLING A PATIENT SUSPECTED OF HAVING A HIGHLY CONTAGIOUS DISEASE}

A basic barrier package was added to all emergency vehicles in the South Moravian Region for better protection of exit group members. This barrier package includes: disposable white overalls (Shield Plus type), half mask with FFP2 filter (captures $94 \%$ of airborne particles), goggles, medical history guide and VNN risk assessment, how to proceed with a positive medical history and examination. [4]

\section{BIOHAZARD TEAM}

The Biohazard Team was established on 28 May 2003 as part of the South Bohemian Region's Outbreak Group for High-Risk Diseases. It is a unique project in the Czech Republic. In addition to the emergency medical service of the South Bohemian Region, the Regional Hygiene Station of the South Bohemian Region in České Budějovice, the Infectious Department of the Hospital in České Budějovice and, if necessary, other components such as the Police of the Czech Republic, the Fire Rescue Service of the Czech Republic and the University Hospital Na Bulovce. The goal of this team was to recognize and isolate the patient in time with a highly dangerous infection without endangering others and providing the infected patient with the best possible care. Highly dangerous infections are infections caused by biological agents, according to regulation 361/2007 Coll., Government Regulation, which lays down conditions for health protection at work. 5210-5219. Nowadays, other teams of this nature are being built, but everything depends on the funds and possibilities of regional hospitals. Nowadays, there are already more modern means of equipping these intervening vehicles on our market. [4]

\section{PROCEDURE OF THE EMS AT THE OCCURRENCE OF VNN}

If $\mathrm{VNN}$ is suspected, it is necessary to activate the integrated rescue system and OOVZ. Before entering the outbreak, all medical personnel (usually 3 persons) will use personal protective equipment and the transport insulating means will be checked. After isolating the patient in the person's isolation means, the staff will consider venous entry, possibly multiple venous entry, airway securing, monitor connection, urinary catheter insertion, probing or cooling considerations. For clinical signs of hemorrhagic rash, intravenous antibiotics are possible. If it is necessary to carry out activities with the risk of aerosol formation, only the necessary number of medical personnel is involved. Mainly decontaminate transport means are used for subsequent patient transport. Medical personnel should not take the patient's documentation or personal belongings unless they are enclosed in a person's transport isolator. If artificial pulmonary ventilation is used, when the ventilation device is placed outside the transport means of transport of persons during transport, it is necessary to inform OOVZ, check the equipment of the ventilation device by the prescribed filters, prevent the plastic parts from being disconnected, use of personal protective equipment during the transport until the decontamination, do not use a humidifier and capnometer with an outlet outside the person's transport means of transport and use a ventilating device with exhalation into the transport insulating agent. [5]

\section{CLASSIFICATION OF MEDICAL DEVICES}

Medical devices are classified according to the degree of health risk associated with the use of the medical device in risk classes I, IIa, IIb or III, ranked in ascending order of health risk corresponding to the use of the medical device, represented by the use of a medical device for the user, or for another natural person; unless they are active implantable medical devices and in vitro diagnostic medical devices; specifying the rules for classification in the abovementioned classes is given by the implementing legal regulation. Classification of medical devices in some of the above classes is carried out according to the rules set out in Annex IX of Council Directive 93/42 / EEC on medical devices, as amended. [5]

Furthermore, in vitro diagnostic medical devices are classified according to List A and List B, medical devices for self-testing and other; specification of lists A and B shall be specified in an implementing legal regulation. Medical devices are also classified according to generic groups. A generic class of medical devices is considered to be a set of medical devices having the same or similar intended purpose or common technology, thereby allowing their classification generically without taking into account the characteristics of the particular medical device. Similar to previous divisions, specific regulation of generic groups are set out in an implementing legal regulation. [6]

\section{RLP VEHICLE AND ITS EQUIPMENT}

Vehicle RLPjesanitní vehicle that meets the conditions for the operation of motor vehicles on the road (according to other legislation). The basic color of the vehicle body is yellow, on the sides of the vehicle there is a retroreflective marking in green and yellow and the vehicle is marked on the sides with the inscription "ZZS". [7]

\section{MERCEDES-BENZ SPRINTER 320 CDI}

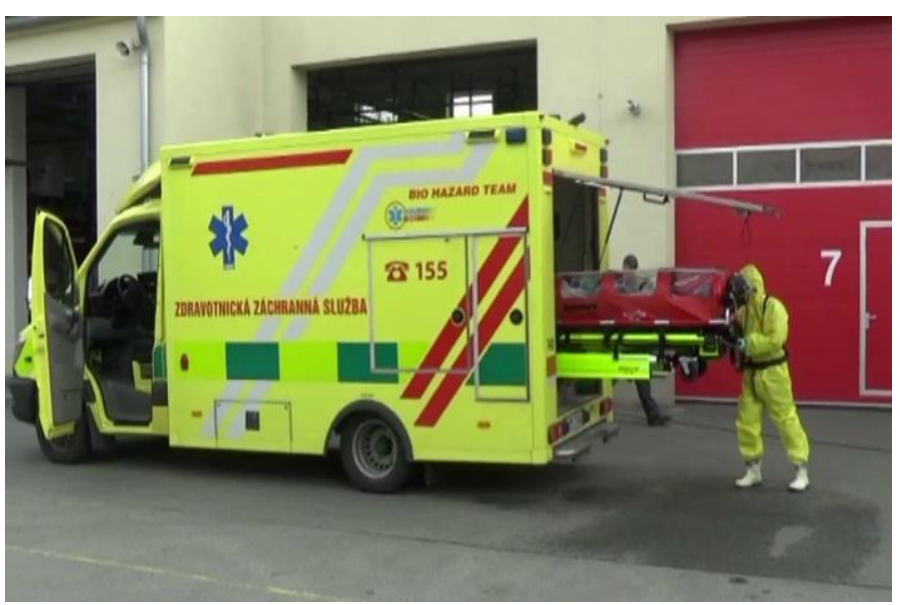

Figure 1. Transport ambulance (source: own) 
The vehicle is the first in the Czech Republic to have a completely separate driver's cab and superstructure, ie ambulatory space. For communication, both parts are intercom interconnected by the crew $\mathrm{u}$ patient communicate with colleagues in the cabin.

The special features a combination of state-of-the-art technology for fine-filtering the contaminated air through a unit that creates an active vacuum in the superstructure to greatly reduce the risk of microorganism transfer outside the vehicle. At the same time, however, it is designed to be quickly prepared and dismantled for ease of decontamination and disinfection in the event of an outbreak of a highly contagious disease. Thus, all interior spaces, including electrical outlets, appliances and other equipment, are equipped with special protection against penetration of liquids and dust. [7]

There is a special stretcher in the vehicle for the transport of highrisk infectious patients, which allows to replace the classic bed with a transport insulator - so-called biobox. This significantly enhances the quality and safety of the personnel and surroundings. Unlike the previous equipment, it is a solid wall-mounted device that eliminates the risk of rupture or damage. At the same time, the vehicle is equipped with a number of additional wiring and voltage converters $(12 / 230 \mathrm{~V})$ in the outpatient area to help ensure safe transport of patients with life-threatening functions. On board, for example, patients who require temporary mechanical support of the blood circulation, extra-pulmonary ventilation can be carried. and so on, because the devices used in these cases often only operate at $220 \mathrm{~V}$ for a long time. Every year ZZS MSK implements several such specialized secondary transports. The new, specially designed and spacious vehicle not only greatly reduces the time required for the technical preparation of these interventions, but also increases the comfort of patients and staff. [8]

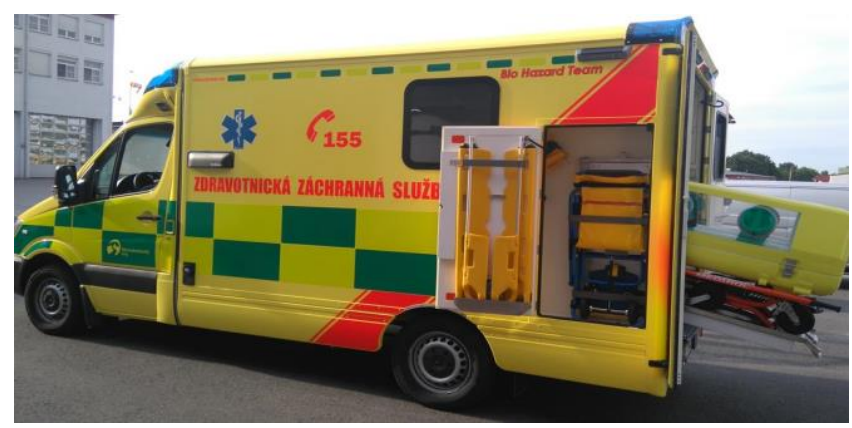

Figure 2. Transport ambulance (source: own)

The vehicle is equipped with a special stretcher with a hydraulic drive to transport patients weighing up to $300 \mathrm{~kg}$. Their loading area can be extended up to $1,120 \mathrm{~mm}$. A new ambulance designed for special patient transports. It distinguishes itself from other ambulances by its quite exceptional arrangement and equipment. It is intended for intervention in patients with highly contagious diseases, as well as in patients with life failure. The vehicle is the first in the Czech Republic to have a completely separate driver's cab and superstructure, ie ambulatory space. The special features a combination of state-of-the-art technology for fine-filtering the contaminated air through a unit that creates an active vacuum in the superstructure to greatly reduce the risk of microorganism transfer outside the vehicle. At the same time, however, it is modified inside to quickly prepare and dismantle the exit to a patient suspected of a highly contagious disease to make decontamination and disinfection as easy as possible. At the same time, the vehicle is equipped with a number of additional wiring and voltage converters $(12 / 230 \mathrm{~V})$ in the outpatient area to help ensure safe transport of patients with life-threatening functions. On board, for example, patients who require temporary mechanical support for blood circulation, extra-pulmonary ventilation and the like can be carried. [9]

\section{THE AMBULANCE AROUSED INTEREST ALSO ABROAD}

Almost every emergency medical service is equipped with biovak and related technologies in the Czech Republic. But they are not in a special car. For example, the presentation of an unusual ambulance in Zlín was watched by potential buyers also from Arabic or Russian-speaking countries. Tomas Bata University in Zlín also participated in the development of a special ambulance. [10]

\section{CONCLUSION}

The aim of the article was to acquaint the reader with the issues of epidemiological threats and readiness of IRS units for the transport of infectious patients. We briefly discussed the imported infections where they arise and subsequent transmission of these diseases among the population. Furthermore, we took a closer look at the work of the Biohazard team and in the main section we dealt with a vacuum ambulance, which occupies the main part of the article and is given adequate space. The importance of these plans and crisis situations is crucial to the issue addressed by this article. In the last part we dealt with equipment, usage and benefits in practice. This was followed by the introduction of an ambulance in the Czech Republic, which, however, is not limited to the borders of the Czech Republic, but can be used by IRS units around the world.

\section{ACKNOWLEDGMENTS}

This research was based on the support of the Internal Grant Agency of Tomas Bata University in Zlín, the IGA / FAI / 2020/003 project and the Institute of Security Engineering, Faculty of Applied Informatics.

\section{REFERENCES}

[1] Guidelines for dealing with emergencies in the South Moravian Region. In: [online]. Available from: http://krizport.firebrno.cz/file/2094_1_1/

[2] Beneš, J., Infestious medicine. Prague: Galén, (C) 2009. Protection. 12 (2), pp. 23-26. ISBN 978-80-7262-644-1.

[3] Černý, Z., Infestious diseases. Brno: Institute for Continuing Education of Healthcare Workers, 2015. Protection. 16 (3), pp. 45-47. ISBN 80-7013-241-8.

[4] Biohazard Team Emergency Medical Service of the South Bohemian Region. [online]. 2011 [cit. 2011] Available: http://www.zzsjck.cz/cinnost/biohazard-team/

[5] ROZSYPAL, H., Basics of Infectious Medicine. In Prague: Charles University, Karolinum Publishing House, 2015. ISBN 978-80-246-2932-2.

[6] CZECH REPUBLIC. Law No 22 of 24 January 1997, laying down technical requirements for products which could pose a significant risk to the health or safety of persons, as amended. In: Collection of Laws of the Czech Republic. 2014, Volume 6,p.128.Alsoavailable:https://portal.gov.cz/app/zakony/zakon Info.jsp?idBiblio=44944\&nr=22 2F1997\&rpp=15\#localcontent

[7] Government Order No. 55/2015Coll., Government Regulation and Technical Requirements for Active Implantable Medical Devices. 
[8] Emergency Medical Service, New ZZS vehicle for special transports. [online]. 2016 [cit. 2016] Available: http://www.uszsmsk. cz/Default.aspx?clanek=42201

[9] Czech. Law no. 240 from the year 2000 about crisis management. In Collection of Laws.
[10] EGO Zlín. 2017. Protective clothing. [online]. Available: http://www.egozlin.cz

\section{Columns on Last Page Should Be Made As Close As Possible to Equal Length}

\section{Authors' background}

\begin{tabular}{|c|c|c|c|}
\hline Your Name & Title $^{*}$ & Research Field & Personal website \\
\hline $\begin{array}{l}\text { Marta } \\
\text { Blahova }\end{array}$ & $\begin{array}{l}\text { Phd } \\
\text { candidate }\end{array}$ & $\begin{array}{l}\text { Population } \\
\text { Protection, } \\
\text { Emergency } \\
\text { Management, } \\
\text { High } \\
\text { Contagious } \\
\text { Diseases }\end{array}$ & \\
\hline $\begin{array}{l}\text { Martin } \\
\text { Hromada }\end{array}$ & $\begin{array}{l}\text { Associate } \\
\text { professor }\end{array}$ & $\begin{array}{l}\text { Critical } \\
\text { infrastructure, } \\
\text { emergency } \\
\text { management, } \\
\text { soft targets }\end{array}$ & \\
\hline
\end{tabular}

${ }^{*}$ This form helps us to understand your paper better, the form itself will not be published.

*Title can be chosen from: master student, Phd candidate, assistant professor, lecturer, senior lecturer, associate professor, full professor, research, senior research 